\title{
ASSOCIATION BETWEEN HEIFER TECHNIQUE AND INTRAMUSCULAR INJECTION PAIN \\ ${ }^{1}$ Heba Mohamed Mahmoud El Hapshy, ${ }^{2}$ Wafaa Ismail Sherif Salam, ${ }^{3}$ Amira Ahmed Hassanin, And ${ }^{4}$ Hanan Mohamed Soliman. \\ ${ }^{1.2,3,4}$ Medical-Surgical Nursing Department, Faculty of Nursing-Mansoura University \\ E-mail of corresponding author : Heba_a899@yahoo.com
}

\begin{abstract}
:
Intramuscular injection is common procedure that nurses frequently carry out which causes pain and distress to the patient, Heifer skin tapping technique have positive effect to reduce intramuscular injection pain ,therefore, Aim of the study: was to assess the effectiveness of Heifer Skin Tap Technique on Pain Associated with Intramuscular Injection at the study setting .Methods: Aquasi-experimental research design was conducted at medical and surgical units at Main Mansoura University Hospital . Purposive sample of adult patient admitted through a period of six months from the beginning of March 2014 to the end of August 2014 at above mention setting and who was take IM injection for treatment by vitamins and analgesics and fulfilling the following inclusion criteria. A total of 100 patients with IM in the injection were entered study. Each patient was administered repeated intramuscular injections at the gluteal site. Then pain level with administration of intramuscular injection by traditional technique were compared with pain level with Heifer Skin Tapping Technique. The tools developed and used for data collection were Sociodemographic characteristics and assessment of pain level with Universal Pain Assessment Tool . results The pain perception of patients in terms of pain level of traditional technique was found to be significantly higher than pain level of Heifer skin tapping Technique conclusion that skin tapping technique was effective in reducing pain level of patients. Thus, skin tapping technique can be used as an intervention to reduce pain associated with administration of intramuscular injection
\end{abstract}

Keywords: Heifer Skin Tapping, Pain, Intramuscular Injection .

\section{Introduction:}

The presence of pain is one of the main reasons why people seek health care. Pain is a highly unpleasant and a very personal sensation that cannot be shared with others; it can occupy all a person's thinking, direct all activities and change a person life, Yet, pain is a very difficult concept for a client to communicate; a healthcare provider neither sees nor feels client pain $^{(1)}$. It infiltrates everyday living and can significantly reduce the quality of life for those who are suffering (2). A person's response to pain is shaped by age, emotional state, sociocultural factors, past experiences with pain, the patient's knowledge of pain and the meaning of pain itself $f^{(3)}$.
Injections are the most common health care procedure worldwide. In developing and transitional countries alone, some 16 thousand million injections are administered each year, more than $90 \%$, are given for therapeutic purposes while 5 to $10 \%$ are given for preventive services, including immunization and family planning, The most significant side-effect related to injections is the accompanying pain. Injection pain is related to the penetration of the skin by the needle and to the mechanical and chemical effects of the drug during and after its injection. This pain remains a major obstacle in medication administration in children as well as in their population 
subject to needle-phobia because of the pain experience. The associated pain may thus prevent optimized medical care for these patient ${ }^{(4)}$.

Pain originating from intramuscular (IM) injection should not be underestimated, because it can damage the nurse-patient relationship ${ }^{(5)}$. Providing pain relief is considered a most basic human right, so it is the responsibility of the nurse to use most effective approach to pain control. Nurses are ethically and legally responsible for managing pain and reliving suffering. Effective pain management not only reduces physical discomfort, but also improves quality of life ${ }^{(6)}$.

Helfer skin tap technique offers a painless injection experience. In this technique rhythmic tapping before injection over the skin at the site of injection keeps the muscle relaxed and stimulates large diameter fibers. It provides a mechanical stimulation and distraction during intramuscular injection and thus helps to reduce pain as described in gate control theory by Roger Metzack and Past Wall in 1965.

Aim of the study: The study was conducted to assess the Effectiveness of Heifer Skin Tapping Technique on Pain Associated with Intramuscular Injection .

Materials and Method:

Materials:

Design:

Aquasiexperimental research design was utilized to reach the aims of the study and represent pain as dependent variable and heifer skin tapping technique as independent variable.

\section{Setting:}

The study was carried out in the 'medical and surgical Unit' at Main Mansoura University Hospital.

\section{Subject:}

The present study included 100 adult patients of both sexes, age ranging from 20-60 years, able to communicate verbally
receiving(IM) injections in dorsogluteal muscles, patient taking vitamins and analgesic. , and who consented to participate in the study. each patient will take four injection two by traditional technique and two by Heifer technique then pain level compared .

Tools: TOOL 1: interviewing structure questionnaire: it consisted of four parts

Part 1:sociodemographic characteristics Include Age, Gender ,Marital status , Residence and Educational level.

Part II :Universal Pain Assessment Tool Which consists of 3 parts ; verbal descriptor scale, wong Baker fascial descriptor scle, avtinity Tolrerance scale

1-Verbal Description Scale:

( Zero) $=$ No pain , (1-2)=mild pain , (3$6)=$ moderate pain , $\quad(7-8)=$ sever pain $(9-10)=$ worst pain .

2- Wong- Baker Facial Grimace Scale: (zero)=alert - smiling , (1-2)=no humor - serious flat (3-4)=furroed browpursed lip breath holding

(5-6)=wrinkled nose ,raised upper lips , rapid breathing (7-8)=slow blink (9$10)=$ eye closed ,moaing, crying .

3-Activity Tolerance Scale :

(zero) $=$ no pain,$(1-2)=$ can be ignored , (3-4) =interfere with tasks (5-6) =interfere with concentration, (78)=interfere with basic needs

$(9-10)=$ bed rest required.

$\mathrm{t}$ - Test" was used to compare the pain level and physiological parameters between Helfer Skin Tap Technique and Routine Technique, and it is significant if $(\mathrm{p}<0.05)$.

Method:

Official permission was obtained from the head of the medical and surgical department at the study setting to conduct the study. A verbal consent obtained from the respondents before their inclusion in the study. Nature and aim of the study was explained to each member of the participants. The Content validity of tools was validated by a panel of 7 expertise in 
the field of the study (6 were nurse professors working at faculty of nursing and 1 was medical professor working in faculty of medicine) who had expertise in developing such instruments and the necessary modification was done, Participant was informed about purpose and nature of the study, assured that their identities and responses to questionnaires would be confidential, participation was voluntary and withdrawal at any stage of study,

Each respondents were taken four injection two by traditional technique followed by two by Heifer technique and pain level were compared, also structured interview were done for each patient to collect necessary data to determine relation of other variable and pain level . The investigator places the patient in side-lying position and flexes the knee to relax the muscles. The investigator makes a wide $\mathrm{V}$ with thumb and the rest of the fingers of the non-dominant hand, over the buttocks and taping the skin with middle, ring and little finger of the dominant hand counts $1,2,3$ simultaneously taps the skin and inserting the needle just after that .Each patient will take 4 injections 2 by traditional method and 2 by applying heifer skin tapping technique and pain level co Pain assessment was done during each injection by a clinical instructor in order to avoid personal bias of the investigator by observing patient facial expression to determine pain level. Soon after injection pain assessment was done using 0-10 numerical pain intensity scale by the patient asked what was the pain level ?

also activity tolerance scale was observed by researcher for one hour after administration of medication to assess level of pain and how it affect activity level of patient .

\section{Statistical analysis:}

Data was analyzed using SPSS (Statistical Package for Social Sciences) version 16.0; Descriptive statistics was done using numbers, percentages, standard deviation as well as medians. Analysis of data was conducted using the One Way ANOVA test of significance.

$\leq 0.05 \%$ level of significance was chosen

\section{Results:}

The data collected were analyzed statistically and the results are represented as the following :

Table 1: Comparison Pain level among Samples receiving intramuscular injection by helfer Skin tap technique and routine technique. $\mathrm{N}=100$

The results show that on verbal rating scale, $17 \%$ were reporting no pain , $6 \%$ of them were having worst pain on application of Traditional Technique ,while $40 \%$ reporting no pain ,2\%worst pain on application of Heifer Technique and There was a significant differences between two techniques as $(p=0,002)^{*}$.

Regarding Wong Baker Facial Description Scale , 21\% were alert smiling, $11 \%$ were have eye closed ,moaing and crying on application of Traditional Technique, while $48 \%$ were alert smile ,5\% were have eye closed ,moaing and crying on application of Heifer Technique, and There was a significant differences between two techniques as $(p=0,002)^{*}$

According to Activity Tolerance Scale ,36\% of patient were reporting no pain ,7\% reporting bed rest required on application of Traditional Technique , while $57 \%$ were reporting no pain, no one reporting bed rest required on application of Heifer Technique . and There was a significant differences between two techniques as $(p=0,003)^{*}$ 
Table 1: Comparison Pain level among Samples receiving intramuscular injection by helfer Skin tap technique and routine technique. $N=100$

\begin{tabular}{|c|c|c|c|c|c|c|}
\hline \multirow[t]{2}{*}{ Pain Scale } & \multicolumn{2}{|c|}{$\begin{array}{l}\text { Traditional } \\
\text { technique }\end{array}$} & \multicolumn{2}{|c|}{$\begin{array}{c}\text { Heifer } \\
\text { technique }\end{array}$} & \multirow[t]{2}{*}{ МH } & \multirow[t]{2}{*}{$\mathbf{P}$} \\
\hline & No & $\%$ & No & $\%$ & & \\
\hline $\begin{array}{ll}\text { Verbal Description Scale } \\
\text { - } & \text { No pain } \\
\text { - } & \text { Mild pain } \\
\text { - } & \text { Moderate pain } \\
\text { - } & \text { Sever pain } \\
\text { - } & \text { Worst pain }\end{array}$ & $\begin{array}{c}17 \\
27 \\
39 \\
11 \\
6\end{array}$ & $\begin{array}{c}17.0 \\
27.0 \\
39.0 \\
11.0 \\
6.0\end{array}$ & $\begin{array}{c}40 \\
34 \\
23 \\
1 \\
2\end{array}$ & $\begin{array}{c}40.0 \\
34.0 \\
23.0 \\
1.0 \\
2.0\end{array}$ & 6.8 & $0.002 *$ \\
\hline $\begin{array}{l}\text { Wong Baker facial Grimace } \\
\text { Scale } \\
\text { - } \quad \text { Alert Smiling } \\
\text { - } \quad \text { No humor, Serious flat } \\
\text { - } \quad \text { furrowed Brow, wrinkled } \\
\text { Nose } \\
\text { - } \quad \text { Slow Blink, Open Mouth } \\
\text { - } \quad \text { Eye Closed }\end{array}$ & $\begin{array}{c}21 \\
29 \\
34 \\
5 \\
11\end{array}$ & $\begin{array}{c}21.0 \\
29.0 \\
34.0 \\
5.0 \\
11.0\end{array}$ & $\begin{array}{l}48 \\
32\end{array}$ & $\begin{array}{l}48.0 \\
32.0 \\
13.0 \\
2.0 \\
5.0\end{array}$ & 6.0 & $0.002 *$ \\
\hline $\begin{array}{l}\text { Activity Tolerance Scale } \\
\text { - } \quad \text { No pain } \\
\text { - } \quad \text { Can Be Ignore } \\
\text { - } \quad \text { Interfere with task } \\
\text { Interfere with } \\
\text { concentration } \\
\text { - Interfere with Basic } \\
\text { Need } \\
\text { - } \quad \text { Bed Rest Required }\end{array}$ & $\begin{array}{l}36 \\
40\end{array}$ & $\begin{array}{l}36.0 \\
40.0 \\
22.0 \\
0.0 \\
2.0\end{array}$ & $\begin{array}{l}57 \\
39\end{array}$ & $\begin{array}{l}57.0 \\
39.0 \\
4.0\end{array}$ & 5.1 & $0.003 *$ \\
\hline
\end{tabular}

MH: test of Marginal homogeneity for related groups

$* P<0.05$ (significant

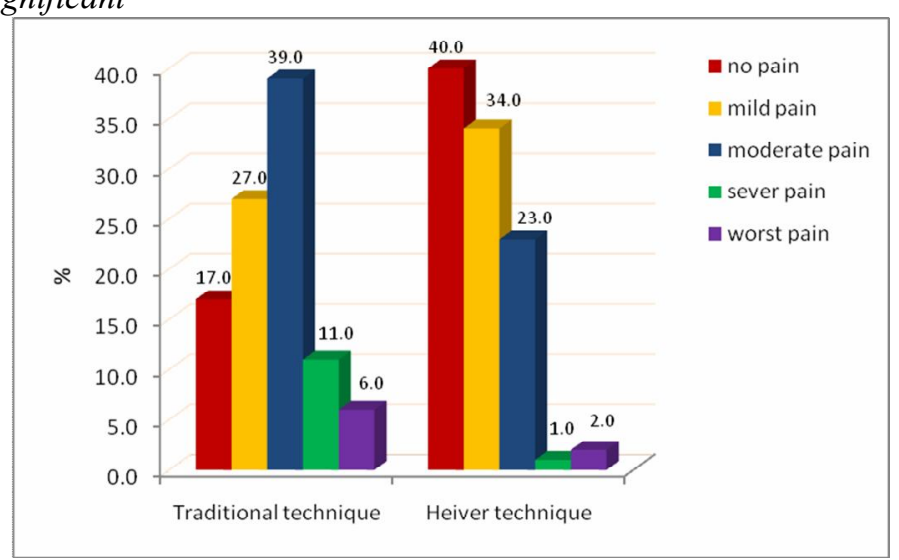

Figure (1): The distribution of Traditional \& Heifer technique by verbal descriptor scale 


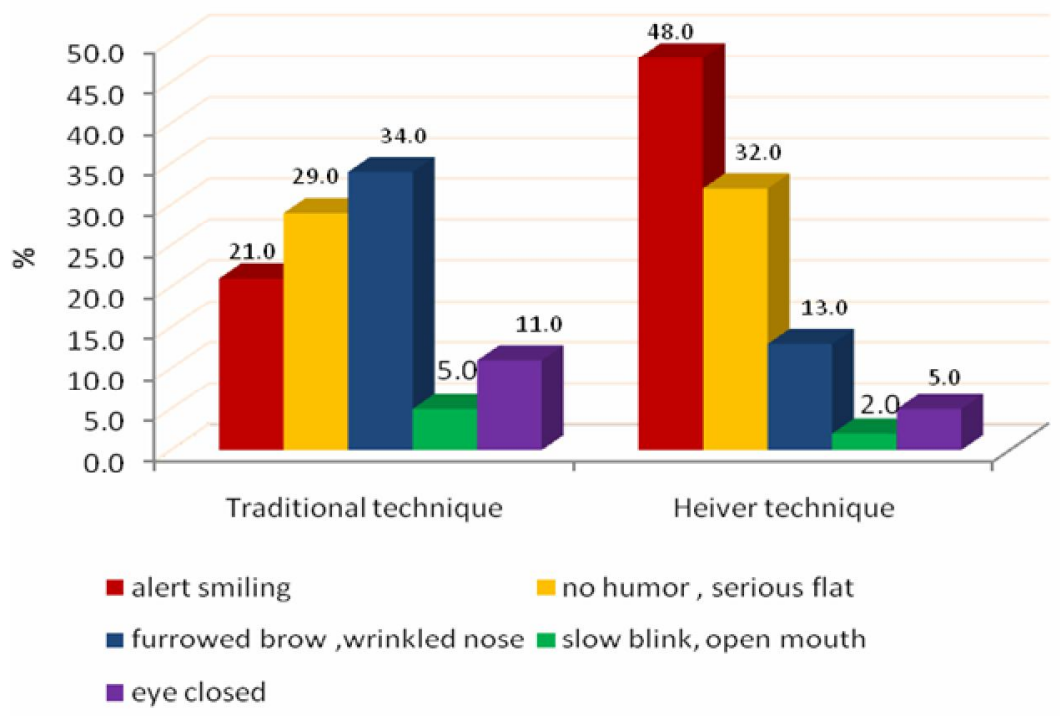

Figure (2): Wong Baker Facial Grimace Description scale in Traditional $\&$ Heifer technique

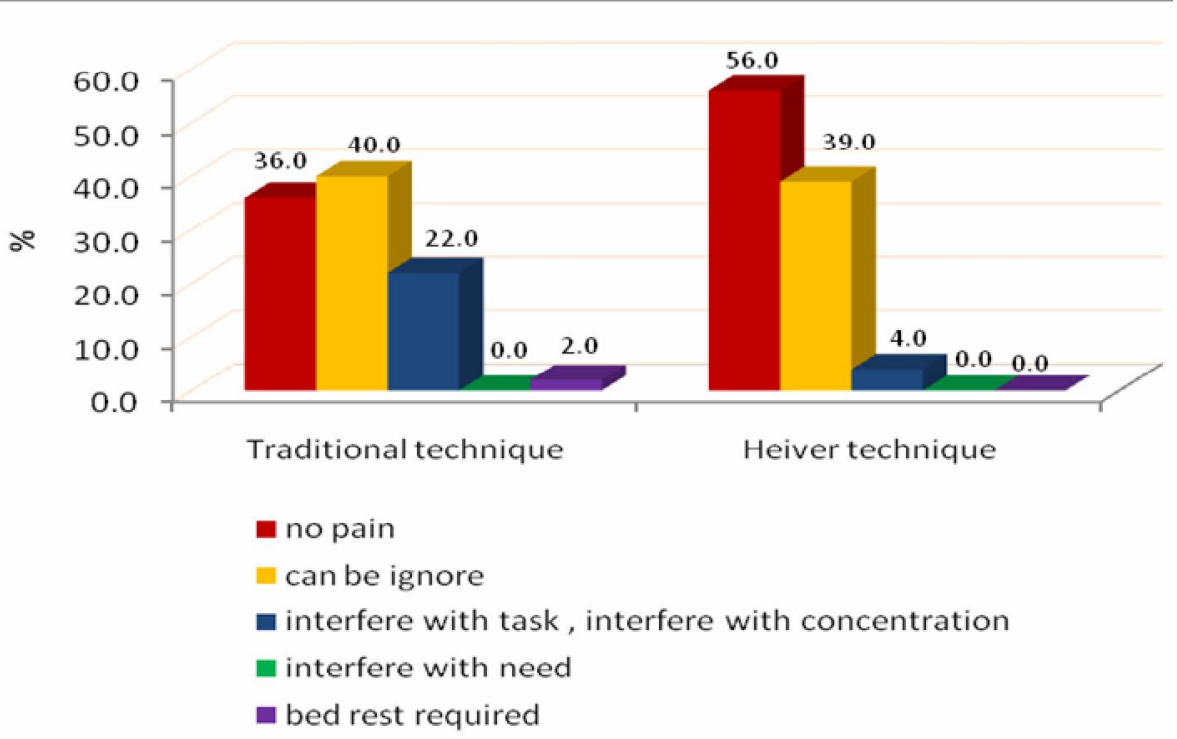

Figure (3): Activity Tolerance scale in Traditional \& Heifer Technique

Table (2) represent Relation of level as mean standard was $6.5 \pm 2.1$ on Sociodemographic characteristics and Pain , Regarding age, the age group from (2029)have the higher pain level as mean standard was $8 \pm 2.4$ on traditional technique and $5.5 \pm 2.5$ on Heifer technique, while the patient aged (50-60) have the lowest pain traditional technique and $5 \pm 1.9$ on Heifer technique . Regarding gender, the female have highest degree of pain mean standard was $8 \pm 2.7$ on traditional technique and $5.8 \pm 2.3$ on Heifer technique . Regarding marital status, the divorced show more 
Heba Mohamed Mahmoud El Hapshy et. al.

pain level with standard was $10 \pm 2$.8on traditional technique and $6.5 \pm .7$ on Heifer technique. while married patient have minimum degree of pain mean standard was $6.5 \pm 2.9$ on traditional technique and $5 \pm 2.3$ on Heifer technique.
Regarding residence, pain level was presented to increase on patient living in urban as mean standard was $8 \pm 2.6$ on traditional technique and $5.7 \pm 2.2$ on Heifer technique

Table (2) Relation of Sociodemographic characteristics and Pain

\begin{tabular}{|c|c|c|c|}
\hline \multirow{2}{*}{$\begin{array}{c}\text { Socio demographic } \\
\text { data }\end{array}$} & $\begin{array}{c}\text { Overall pain } \\
\text { traditional }\end{array}$ & Overall pain Heifer & \multirow[t]{2}{*}{$\mathbf{P}$} \\
\hline & Mean SD & Mean SD & \\
\hline $\begin{array}{cc} & \text { Age } \\
\text { - } & 20-29 \\
\text {. } & 30-39 \\
\text { - } & 40-49 \\
\text { - } & 50-60\end{array}$ & $\begin{array}{l}8.0 \pm 2.8 \\
6.7 \pm 3.0 \\
7.0 \pm 3.0 \\
6.5 \pm 2.1\end{array}$ & $\begin{array}{l}5.5 \pm 2.5 \\
5.0 \pm 2.2 \\
5.4 \pm 2.4 \\
5.0 \pm 1.9\end{array}$ & $\begin{array}{l}0.001 * \\
0.001 * \\
0.001 * \\
0.001 *\end{array}$ \\
\hline $\mathbf{P}+$ & 0.195 & 0.801 & \\
\hline $\begin{array}{ll} & \text { Gender } \\
\text { - } & \text { Male } \\
\text { - } & \text { Female }\end{array}$ & $\begin{array}{l}5.6 \pm 2.3 \\
8.0 \pm 2.7\end{array}$ & $\begin{array}{l}4.3 \pm 1.9 \\
5.8 \pm 2.3\end{array}$ & $\begin{array}{l}0.001 * \\
0.001 *\end{array}$ \\
\hline $\mathbf{P} \#$ & $0.003^{*}$ & $0.006^{*}$ & \\
\hline $\begin{array}{ll}\text { Marital status } \\
\text { - } & \text { Single } \\
\text { - } & \text { Married } \\
\text { - } & \text { Widow } \\
\text { - } & \text { Divorced } \\
\end{array}$ & $\begin{array}{l}7.6 \pm 2.8 \\
6.9 \pm 2.9 \\
7.0 \pm 2.5 \\
10.0 \pm 2.8\end{array}$ & $\begin{array}{l}5.6 \pm 2.7 \\
5.0 \pm 2.3 \\
5.3 \pm 1.9 \\
6.5 \pm 0.7\end{array}$ & $\begin{array}{c}0.001 * \\
0.001 * \\
0.003 * \\
0.074\end{array}$ \\
\hline $\mathbf{P}+$ & 0.372 & 0.662 & \\
\hline \begin{tabular}{ll}
\multicolumn{2}{c}{ Residence } \\
- $\quad$ Rural \\
- $\quad$ Urban \\
\end{tabular} & $\begin{array}{l}6.1 \pm 2.7 \\
8.0 \pm 2.6 \\
\end{array}$ & $\begin{array}{l}4.7 \pm 2.2 \\
5.7 \pm 2.2 \\
\end{array}$ & $\begin{array}{l}0.001 * \\
0.001 *\end{array}$ \\
\hline P\# & $0.003 *$ & $0.031^{*}$ & \\
\hline $\begin{array}{ll} & \text { Education } \\
\text { - } \quad \text { Illiterate } \\
\text { - } & \text { Read and } \\
& \text { write } \\
\text { - } & \text { Middle } \\
& \text { education } \\
\text { - } \quad \begin{array}{l}\text { High } \\
\text { education }\end{array} \\
\end{array}$ & $\begin{array}{l}6.3 \pm 2.6 \\
6.7 \pm 3.1 \\
7.9 \pm 2.7 \\
7.2 \pm 2.7\end{array}$ & $\begin{array}{l}4.8 \pm 2.1 \\
4.7 \pm 1.8 \\
5.6 \pm 2.4 \\
5.8 \pm 2.5 \\
\end{array}$ & $\begin{array}{l}0.001 * \\
0.008^{*} \\
0.001 * \\
0.003^{*}\end{array}$ \\
\hline $\mathbf{P}+$ & 0.241 & 0.504 & \\
\hline $\begin{array}{l}\text { P: Paired t-tes } \\
P^{\#}: \text { Student t-te }\end{array}$ & & $\begin{array}{l}P+: \text { One Way ANOV } \\
* P<0.05 \text { (significant) }\end{array}$ & \\
\hline
\end{tabular}




\section{Discussion:}

Nurses play a greater role in minimizing the pain and discomfort during any invasive procedure. The nurse can minimize the discomfort and pain during Intra muscular injection by helping the client to assume a proper position and by implementation of different physical, psychological interventions . Physical interventions and injection techniques that minimize pain during injection offer an advantage over other techniques because they can be easily incorporated into clinical practice without added cost or time. $^{(6)}$ ), The study was conducted to evaluate the effectiveness of Helfer Skin Tap Technique and traditional Technique on Pain Reduction associated with Intramuscular Injection ,. Shimmy, (2010) conducted a randomized control trial in chandigarh to assess the skin tap technique on pain during

intra muscular injection among adult patients receiving intra muscular analgesic injection. It was observed that mean pain score of control group was $2.94 \pm 1.68$ and the experimental group was 2.08 \pm 1.26 . The difference was statistically significant $(p<0.05)$. It was concluded that perception of pain intensity is less when intra muscular injections are administered using skin tap technique. In this study it was found that the perception of pain intensity is less when intra muscular injections are administered using Helfer Skin Tap Technique rather than routine technique ${ }^{(7)}$ - Serena, (2010) conducted a quasi experimental study (one group pre test and post test design) was conducted on 60 patients in Karnataka, India to assess the effectiveness of Helfer skin tap technique on pain in relation to intramuscular injection. Study revealed that the paired $t-$ test was significant at $p<0.001$. Maria ,(2012) revealed that the effectiveness of Helfer Skin Tap Technique has produced a statistically highly significant in reducing pain during intra muscular injection among patients at a correlation of $\mathrm{p}<0.05$ level. ${ }^{(8,9)}$.

In present study also it revealed that the effectiveness of Helfer Skin Tap Technique has produced a statistically highly significant in reducing pain during intra muscular injection among patients at a correlation of $\mathrm{p}<0.05$ level. On All scales used to assess pain, Helfer skin tap technique is statistically significant than traditional technique. It clearly shows that there is significant reduction of the pain level using Helfer Skin tap Technique than traditional Technique among patients receiving intra muscular injection.

According to other variable included in the study, it represented that there was significant relation between pain level and all sociodemographic characteristics that include ( age , sex , marital status, residence and educational level )and I was also founded that pain level increase in the age group (20- 29) and decrease in age group (50 -59) This was congruent with Ozdemir (2010) who said that said that patient on these age group have more pain. ${ }^{(10)}$

In relation to sex of patients female have higher pain level than male and this was in line with Jerin (2011) founded that the mean value of pain level is greater in female than male. ${ }^{(, 11)}$

Concerning to marital status , these results revealed that pain level increased in divorced patient, and these was in line with Antonio et al (2012) said that divorced and separation have increase pain level . ${ }^{(12)}$

As regarding to education, the present study showed that middle education have more pain level while illiteracy have less pain , these also near to Ozdemir( 2010). said that patient with higher level of education have more pain intensity, And this was in disagreement with Kim (2010) who demonstrated that lower educational 
attainment was associated with increased pain intensity and disability ${ }^{(13)}$

According to residence, the present study showed that pain level increased in people coming from urban than rural areas . This is supported by Tripp, (2006) who said that being female, low income and rural residence associated with greater pain, on the other side Brzeziński $\mathrm{K}$ (2013) said that the place of residence doesn't affect pain intensity. ${ }^{(14,15)}$

\section{Conclusion:}

The following conclusions were drawn from the study. The study proved that Helfer Skin Tap Technique was effective than the traditional Technique in administering Intra Muscular Injection with mild pain or no pain and there is an association between Helfer Skin Tap Technique and sociodemographic characteristics that include ( age , sex , marital status, residence and educational level and no association on the type of medication. It was concluded that the perception of pain intensity is less when intra muscular injection is administered using Helfer Skin Tap Technique. It works on the theoretical basis such as gate control theory. The technique can be adapted to the nursing education and to the nursing practice so that the quality can be ensured .

\section{Recommendations:}

The current study projects the following recommendations:

1-The study can be replicated on a large sample in order to validate the findings and make generalizations.

2- An experimental comparative study could be done with four groups design where rhythmic skin tapping could be done with varying frequencies in each group, to evaluate the effective range of frequency in minimizing pain.

3- A multi-group study can be done comparing other indigenous techniques like application of cold, massage therapy, music therapy etc. to evaluate the effectiveness of these techniques on pain perception by the patients while receiving IM injection.

4-This study can be used as an informative illustration for staff nurses working in different wards, OPD, immunization department for managing patients with pain at the site of injection.

\section{Acknowledgements:}

We would like to thank all the patients' and staff of the medical and surgical unit for their help and cooperation during the study period and appreciate the great efforts of our supervisors in this work.

\section{Corresponding author:}

Heba Mohamed Mahmoud

Medical Surgical Nursing Department, Faculty of Nursing-Mansoura University.

\section{References:}

1-Modi,2010. Nursing student's Knowledge and application of pain assessment at King Saud University Master's Degree in Medical Surgical Nursing .

2-D'Arcy Y. 2007 Pain Management: Evidence-Based Tools and Techniques for Nursing Professionals. Marblehead, Mass

3-Burke, K.M. Mohn-Brown, E.L. \& Eby, L. 2011. Medical Surgical Nursing Care. 3rd edition. Pearson: USA. 133, 151, 153, 181, 265, 267-268, 281, 303

4-Kanika , k (2011) Effect of massage on pain perception after administration of, Intramuscular Injection among adult patients. Available at Nursing and Midwifery Research Journal, Vol-7, No. 3, July 2011

5-Suhrabi Z, Taghinejad H. 2014 Effect of acupressure (UB32) on pain intensity in intramuscular injections. Iranian Journal of Nursing and Midwifery Research | January-February 2014 | Vol. 19

6-Gitanjali Zore, ,2014Effectiveness of Nursing Interventions on Pain Associated With Intramuscular 
Injection, M. Sc Nursing, Institute of Nursing Education, J. J.Hospital Campus Mumbai 8, Maharashtra, India, Volume 3 Issue 6, June 2014 www.ijsr.net

8- Sr. Serena. Rhythmic skin tapping: An effective measure to reduce procedural pain during IM injection. Available

from: www.tnaionline.org/aug10/6.htm.

9- Maria. 2014, Effectiveness of Helfer Skin Tap Technique and Routine Technique on Pain Reduction among Patients Receiving Intramuscular Injection at Government General Research Institute of Health Sciences, Puducherry Volume 3 Issue 10, October 2014

10-Ozdemir L, Punarcı E, Nisa Akay B, Akyol A. Effect of Methylprednisolone Injection Speed on the Perception of Intramuscular Injection Pain. Pain Manag Nurs. 2010; 14:3-10.

11- Jerin , 2011, An experimental study on the use of manual pressure to reduce pain in intramuscular injections among nursing students in a selected nursing college, Bangalore. R.R.College of nursing, Raja Reddy Layout, Chikkabanavara,
12-Antonio,etal, 2012, Influence of sociodemographic factors upon pain intensity in patients with temporomandibular joint disorders seen in the primary care setting ISSN-e 16986946, Vol. 17, No. 6, 2012

13-Kim HJ 2012 ,Influence of educational attainment on pain intensity and disability in patients with lumbar spinal stenosis: mediation effect of pain catastrophizing. Volume 14, Issue 11, Supplement, Pages S148-S149

14-Tripp2006 , Prevalence and determinants of pain and pain-related disability in urban and rural settings in southeastern Ontario , PhD1, Elizabeth G VanDenKerkhof RN DrPH2, Margo McAlister BA3 ,. Pain Res Manage Vol 11 No 4 Winter 2006

15- Brzeziński K 2013, Comparison of the efficacy of dexketoprofen and diclofenac in treatment of non-specific low back pain PubMed2013; Spec no. 1:52-6. 